\title{
The Construction of Archives Informatization Seen from Supply-side Reform
}

\author{
Shi-chen Chen \\ Archives \\ Quanzhou Normal University \\ Quanzhou, China \\ 844149688@qq.com
}

\begin{abstract}
The construction of archives informatization is the inevitable trend in this age, and it has important significance in promoting the development of archival cause. The principal contradiction of archival supply-side cause intensively reflects in satisfying well the demands of the national production and people's lives at present. The author wanted to find the ways to resolve conflict above. The main ways of solving the supply-side structural contradictions are strengthening and improving the construction of archives informatization, promoting the supply-side structural reform on three aspects of system, mechanism and technology, increasing total factor productivity. This paper provides new methods in the view of supply-side structural reform. Specifically, we should strengthen archival infrastructure construction, standardization construction, resources construction, service functions and safety guarantee.
\end{abstract}

Keywords-archives; supply-side contradictions; informatization construction; reform

\section{INTRODUCTION}

Supply-side is an economic concept. In November 2015, supply-side reform was proposed by $\mathrm{Xi}$ Jinping in the 11th conference of the Central Leading Group on Financial and Economic for the first time. The supply-side reform has become the main direction and important content at present. There are relations between supply \& demand and supply-side in the field of archives work, which is a very important part of the development of the Party and the nation. [1] So, deepening the supply-side reform, improving the quality and level of archives management, and improving the quality of archives service of supply system are all necessary to archives work. As to the development of the archival cause these years, deepening archives informatization construction is the important way to solving the supply-side contradiction of archival cause in this country ,to improving the quality \& level of servicing the development of the Party and the nation and livelihood.

\section{The Important Significance of ARChIVES INFORMATIZATION CONSTRUCTION}

Archives informatization can be regarded as a comprehensive system which is led by widely applicable information technology, the core of construction of archives information resources, the base of information networks, relying on information talents, and guarantee of regulations, policy \& standard of archives information. Informatization must experience the stage which is being constantly perfected, while not result of one moment. [2]

1. It is the demand of economic and social development for the construction of archives informatization. With the rapid development of science \& technology, informatization characterized by digitization, network \& intellectualization is involving itself in people's production and life. Informatization is national important development strategy. To implement a strategic transition quickly, based on the instructions of the Party Central Committee and the State Council, the archival cause should follow up and be involved deeply into national informatization strategic layout, especially the development program of E-Government, Big Data, cloud computing and artificial intelligence.

2. It is the demand of electronic documents of large amount for the construction of archives informatization. With the massive growth in electronic documents, it's informatization construction after the necking. According to the research report by IDC, the share of electronic documents in China in the world will increase to 21\% from 13\% from 2012 to 2020.[3] Facing the surprisingly quantity of electronic documents, the idea, content \& method of archives work should be changed accordingly. Accelerating the urbanization process of informatization is the most fundamental and effective way. Archival cause must act as the times demand for the right moment, accelerate advancing the archives informatization, so that archival modernization of management with the core of informatization will be realized gradually.

3. It is the demand of supply-side reform of archival cause for the construction of archives informatization. The same as economic field, there are problems of unmatched supply and demand, requirement for supply-side reform in the field of archival cause. The emphasis of supply-side reform is increasing total factor productivity, eliminating backward production capacity, increasing effective supply. Deepening the supply-side reform of archival cause is improving upgrading archival service the sticking point of which is concentrating supply-side reform of archival cause, decreasing invalid and low-end supply, increasing valid and high-end supply, enhancing adaptation \& flexibility of supply system to demand changes. [1] Based on economic theory, the essence of structural supply-side reform is promoting structural reform on the levels of system, mechanism \& technology, regarding the supply-side as break-through of reform. [4]Accelerating the 
informatization process and promoting normalization, standardization \& scientization of archives management is one of the most effective approaches to solving the supply-side structural contradictions of archival cause.

\section{The Principal Contradiction of SupPly-Side of ARCHIVAl CAUSE}

The archival cause grew vigorously and the construction of archives informatization is particularly outstanding in recent years. The informatization system, based on infrastructure of archives informatization, led by the standard system of archival informatization standard, based on the construction of archives information resources, for purpose of archival information service, safeguarded by information security, has been built. [5] It should be noted that along with rapid social networked \& informationalized development, the demand of archival service system from economic and social development is increasing day by day. Compared with the new requirement of the Party and Country, with the new expectations of the people, with the new trend of the development of network information age, there's lots of shortage manifestation of which is the relatively prominent principal contradiction of supply-side.

1. The idea of construction of archives informatization remains to be changed. With the joint efforts of all the archives workers, the archives informatization construction develops rapidly, but it remains further knowledge to archives informatization construction. The emphasis of construction of archives informatization is not just improving the technicality, but changing mind, perfecting system \& implementing every task, especially implementing the task of informatization mainly of which is the construction of archives information resources.

2. The standard system of archival informatization standard is not consummate. Standardization is not only the base \& premise of informatization but also the navigator \& booster of it. Only when standardization is achieved in archives work can the possibility of the interconnection, interworking and sharing of digital archives be achieved. First, it is insufficient to manage archives according to laws. After National Archival Law being revised, the speed of construction of matched laws and regulations is still slow. Although lots of department regulations as well as industry standard have been formulated, the national standard is still less. There is a few shortages compared with the request of standardization law revised newly. Second, it is insufficient to normalization of archival basic work, such as accession, settlement, storage and utilization. The normalization and scientization of basic work is essential to informatization. Because some leaders and staffs discount the basic work in their minds, which leading to weak basic business, non-conformant standard and nonstandard operation in the working links of accession, settlement, appraisal, recording and storage. All above will influence archives informatization and digitization in the next step. Third, operation evaluation is not sufficient. The evaluating system that covers all archival business field has initially formed, but the evaluation work has not formed a long-term and effective system, the evaluation content does not highlight job performance, the evaluation result does not lead to effective application, so that the target to perform responsibilities and to proceed the arise has not been realized.

3. The construction of digital archives resources is not perfect. Compared with the requirement of archives informatization construction, the construction of digital archives resources is not perfect till now. First, you can see structural imbalance in the archives resources. Because the emphasis of construction of archives resources formerly is Party and government offices and important enterprises and institutions, most of the archives are administrative documents while not archives of sci-tech, the people's livelihood or classified archives. There are serious problems of the collection in many archives, such as structural imbalance, incomplete category and consubstantial trend. Second, the archives is still short of informatization. To digitally process those paper archives, many archival departments threw in vast amount of resource but led to considerable waste for in short of scientific planning and careful discrimination. Because of the low level of informatization and digitization, copying and transferring electronic documents are regarded as archives electronization by some organizations, so the authenticity, reliability, integrity and availability of electronic documents is difficult to be guaranteed. Third, the degree of resource sharing and system integration is lower. The degree of information system integration and digital resource sharing between archival departments, between archival departments and other departments is low now. So it's difficult to make overall plans and share.

4. The ability of archival information service needs to be improved. The basic purpose of archives work is serving national production and people's living, but the ability of archival information service can not satisfy the demands well now. First, the level of service is insufficient. Because many archival departments do not keep up with the national economic and social developing situation or be actively involved in the overall developing situation of social informatization, they lack comprehensive data mining and further integration. Because of lack of statistics \& compiling and studying, the service of those archival departments cannot satisfy the demands of the development of the Party and the nation. Second, the ability of service is insufficient. Most of the livelihood archives, such as medical treatment, education, social security, etc. which are closely related to the fundamental interests of the people, are not placed under centralized and unified management while dispersedly stored in every related departments. The unbalance and insufficiency of the collection of livelihood archives resource acted counter to the requirement of service. This leads to the structural contradiction between demand and supply, and going against serving the people's livelihood. Third, the quality of the users' experience is generally low. The staff of most archival departments is waiting for the orders from external service in the offices. Because they cannot provide thoughtful service such as telephone reservation, networks appointment, distance utilization, mobile phone consultation, etc.

5. The ability of archival information safety is not enough. First, the safety guarantee system of archives information is imperfect. Some problems exist in safety guarantee system of archives information in the aspect of management system, 
facilities system, standard system and technical system. All above are below this specified requirement of classified security protection of information safety and hierarchical security protection of secrecy work, and cannot provide construction of archives informatization with good safety guarantee. Second, the management rules and regulations are not in place. Although many archival safety rules and regulations were enacted, there are still potential security exposure combined with the human, substance and technology prevention for weak consciousness and poor management. And the loss is irreparable. Third, the ability of disaster recovery backup is inadequate. Faced with inescapable natural and man-made calamities, usually people can do nothing because of shortage of risk consciousness and archival disaster recovery backup system.

\section{DEEPENING SUPPLY-Side REFORM AND STRENGTHENING ARCHIVES INFORMATIZATION CONSTRUCTION}

Xi Jinping stressed that to promote supply-side reform, we can't wait because of heavy burden, act of omission because of a sea of troubles, back away from risks, stagnate because of painful process. [6] About supply-side reform of archival cause, that what to reform and how to reform is improving the structure and improving the service. Around current supply-side structural contradictions of archival cause, by considering the logic of reform itself and the actual situation of the development of archival cause in China, we must stick to problem-oriented and accurately improve weak links. So we can pertinently promote the reformation of archives informatization construction. The goal of reform is, modernization of archives management, with the core of informationization will be preliminary realized, and development framework of archival cause which adapts to building moderately prosperous society and effectively service national governance and the five-pronged approach construction (balanced economic, political, cultural, social and ecological progress ) by 2020. [7]

1. Strengthening archival infrastructure construction. The local governments and archival departments should increase input to make overall plans for archives informatization infrastructure construction. Firstly, improving archival infrastructure construction. Increasing input to make notable progress in storehouse reconstruction, construction of computer room and hardware equipment of archival departments. Secondly, strengthening construction of networks infrastructure. Strengthening the constructions of website construction, software platform, computer network and database system to raise running speed ,to increase storage capacity, to push forward interconnection and cooperation. The comprehensive networking among LAN of archives business, government affairs network and Internet will be realized finally.

2. Strengthening standardization construction. Standardization is an important factor in archives informatization construction. The focus of archives standardization construction is on improving the quality of revision work of archival standard system in three areas of applicability, advancement and normalization, especially increasing effective supply of archival standard by strengthening research of standard of information integration and sharing, improving and optimizing archival standard system at present. [1]Firstly, the archives legislation should be strengthened and managing archives according to laws should be promoted. Laws and regulations are the foundation and basis of standardization construction. Only with solid the foundation of supporting concerned policy construction will the work of electronic documents management standard construction in China make healthy and orderly progress. [8] The archival laws and regulations which correspond with Standardization Law should be improved, the administrative law enforcement should be perfected, and the administrative inspection over archives should be strengthened. Secondly, the necessary standards and specifications should be made. To realize the archival standardization in the whole progress of collection, storage, management and utilization, the development program, business standard and management system of archives informatization construction must be improved, the standards and specifications of electronic documents management and utilization in the important field of urban construction, citizen credit and medical treatment must be made and improved, the business process and technical specification of archives management must be improved. Thirdly, the operation evaluation should be strengthened. Based on the evaluation work of general archives operation construction, to start from improving the level of normalization and scientization of archives informatization construction, the evaluating system of normalization and scientization of archives informatization must be explored.

3. Strengthening archives resources construction. Archives resources construction is an important factor in archives informatization construction. Firstly, the archives resources system which benefit the people should be established and perfected. To serve key work, economic construction and the people's livelihood better, we must strengthen archives resources construction and improve a more complete, more abundant and pluralistic archives resources system which benefit the people better. Secondly, the centre of digital archives resource should be built. Based on the centre of digital archives resource, the resources interconnection and sharing must be strengthened. Meanwhile, to promote the overall construction, standardized management and effective utilization of archives resource, the construction of archives directory centre, archives utilization centre, publicizing government information referral centre and electronic documents data recovering centre must be actively promoted. Thirdly, the digital archives should be built. In the third collective study of Political Bureau of the CPC Central Committee of the 19th Central Committee of the Communist Party of China, General Secretary Xi Jinping emphasized the necessity of using big data to improve governance. A nationwide information-sharing platform should be set up with the use of e-government and smart city systems. [9] Exploiting, obtaining, analyzing and utilizing data, which is the important content in archives construction, can provide the possibility for the integration of archives information system and the sharing of archives digital resources, and provide support for serving the Party ,our country and people's livelihood better. 
4. Strengthening the service functions. The final goal of supply-side reform is serving the national economic and social development, the people's utilization and various undertakings' development better. Firstly, fastening the sharing of archives information resources. The national management system of archival business has formed a fairly large scale at present and the simple implementation of business collaboration among archival departments is realized with 28 vice-provincial and municipalities archival departments being connected and working. We should further raise the level of system's cooperation with digital archives resources project of fusion, sharing and service. A open service platform where information can be integrated and sharing can be realizedmust be built. Secondly, expanding the service channel. According to The 41st Statistical Report of Chinese Internet Development Status released by China Internet Network Information Center (CNNIC), the number of Chinese netizen is 7.72 hundred million and the number of internet users on mobile phones is 7.53 hundred million by the time of December.[10] To closely follow the social development, the archives informatization construction must strengthen the construction of internet and mobile terminal. The limits of time and space will be broken down by expanding gradually those new service, such as on-line inquiry and remote service. Especially using for reference from mobile library, we can exploit mobile archives to improve the intellectualization of mobile terminal services. Thirdly, enhancing user experiences. The service transformation and upgrading should be promoted with the focus on customer needs. To improve the social satisfaction of archival public service, the traditional archival service of waiting for the orders in offices must be changed to the experience service of detective service with affiliation and customization service. Fourthly, enlarging government purchased services. According to Guiding Opinion on Government Purchased Services from Social Forces released by the State Council, in view of the shortage of personnel and technology in archival departments, the management idea must be changed. To improve the efficiency and level of construction of archives informatization, the archives service enterprises should be led to orderly join in the jobs of archival management, especially archival technical jobs of digitization, electronization and network.

5. Strengthening archives safety guarantee. Firstly, ensuring the archival safety of entity and information. Improving the environment and strengthening the safety management of archives storehouse, the standard requirements and control measures of storehouse safety are strictly carried out for the convenient use of archives. The management of hierarchy and classification should be strengthened and all the information which is limited to be declassified could not be blasted online, even it must be physically isolated from network by some essential means. Establishing the safety emergency response mechanism and recovery mechanism, such as disaster recovery, remote-backup, heterogeneous backup, etc. by using risk management concept and means, so the risks can be prevented and the losses caused by risks can be reduced furthest. Thirdly, establishing national strategy for electronic documents management. The emphasis of archives information safety is electronic documents management. The national strategy for electronic documents management is the concrete practice and vector of Chinese informatization strategy, and very important part of informatization strategy. Establishing national strategy for electronic documents management, at national level and on the view of strategy, is the target location, overall planning and basic systems arrangements of those problems of globality, fundamentality and chronicity. Its essence is researching and resolving the problems of electronic documents management on the view of strategy. [11] Establishing national strategy for electronic documents management in archives informatization construction, which can improve archives safety guarantee system, preventing from major risks, and upgrading the management level of electronic documents management, is the practice of fully implementing general national security concept.

\section{CONCLUSION}

Supply-side reform is not only an economic concept but also a mode of thinking what can help us to solve problems in other fields. The modes of supply-side reform, such as globality, systematicness, innovativeness and dialectics, were proved to be useful in our work. In archives informatization construction, that traditional pattern of thinking must be replaced in the view of supply-side structural reform. We should promote the supply-side structural reform on three aspects of system, mechanism and technology, increasing total factor productivity. We should devote attention to addressing unbalanced and insufficient development. With these new modes, national strategy, supply system, resource sharing, utilization demand and risk consciousness, archives departments will promote building the informatization construction at a higher level.

\section{REFERENCES}

[1] Li Ming-hua, Work Report at National Conference of Archives Directors and Curators[N].CHINESE ARCHIVES WEEKLY, 2018-1-22(1) .(In Chinese).

[2] Zhou Ling, Thoughts on Construction of Archives Informatization [J].ARCHIVES SCIENCE BULLETIN,2003(6):22.(In Chinese)..

[3] IDC: Digital World in China is Expected to Increased by 24 Times by 2020 [DB/OL]. China Internet Network Information Center, http://www.199it.com/archives/203071.html.(In Chinese).

[4] Feng Zhi-feng, On the Theory Logic and Practice Path to Structural Reform of the Supply Front [J].ON ECONOMIC PROBLEMS, 2016(2): 14. (In Chinese).

[5] Wang Da-zong,l Laying a Solid Foundation, Exploiting and Innovating, Ensure the Safety-The Construction of Archives Informatization is Becoming More Complete since the 18th National Congress of the Communist Party of China (CPC) [N] CHINESE ARCHIVES WEEKLY,2017-9-7(1).(In Chinese).

[6] Firmly Advance Supply-side Structural Reform, and Continually Expanding the Middle-income Group under the Development [N]GUANGMING DAILY,2016-5-17(1).( In Chinese)..

[7] The 13th Five-Year Plan for National Archives Cause Developmen [DB/OL ].State Archives Administration of PRC, http://www.saac.gov.cn/news/2016-04/07/content_136280.htm.(In Chinese).

[8] Feng Hui-ling, Liu Yue-nan. National Strategy of Electronic Records Management[M] CHINA RENMIN UNIVERCITY PRESS: 2011: 296. (In Chinese).

[9] China Must Accelerate Implementation of Big Data Strategy: Xi [DB/OL] CHINA DAILY, 
http://www.chinadaily.com.cn/a/201712/09/WS5a 2bba55a310eefe3e9a 1 2ea.html.

[10] The 41st Statistical Report of Chinese Internet Development Status [DB/OL]. China Internet Network Information Center (CNNIC), http://www.cnnic.net.cn/gywm/xwzx/rd xw/201801/t20180131_70188.ht $\mathrm{m}$.( In Chinese) .

[11] Feng Hui-ling, Liu Yue-nan. National Strategy of Electronic Records Management[M] CHINA RENMIN UNIVERCITY PRESS:2011:52. (In Chinese). 